\title{
Effects of feeding phytogenic substances and phytase on growth performance and nutrient digestibility of young broilers
}

\begin{abstract}
The effect of feeding phytogenic feed additive (Biostrong®, BS510) and microbial phytase (Natuphos® 5000) on the growth performance and nutrient digestibility in broiler chickens was studied. A total of 280 male Ross broilers were raised from day old until $21 \mathrm{~d}$ of age under 3-tier cage system. The chicks were divided into 5 groups: Controlð Basal diet; T1: Basal diet + phytase (using 100\% matrix value of phytase); T2: Basal diet + BS510 (using $100 \%$ matrix value of BS510); T3: Basal diet + phytase (using 100\% matrix value of phytase) + BS510 (without matrix) and T4: Basal diet + phytase (using 100\% matrix value of phytase) + BS510 (using only $100 \% \mathrm{Ca}, \mathrm{P}$ matrix value of BS510). The birds fed with phytase or phytogenic substances or combinations had better growth performance than the control. The diets added with phytogenic substances and phytase had better digestibility of nutrients such as crude protein, phosphorus and calcium. It is concluded that both additives can be used in broiler chicken diet with advantage.
\end{abstract}

Keyword: Phytogenic feed additive; Phytase; Nutrients; Digestibility; Broiler 